\title{
Right ventricular free wall strain predicts quality of life in repaired tetralogy of Fallot
}

\author{
Jimmy C Lu ${ }^{1,2^{*}}$, Maryam Ghadimi Mahani², Prachi Agarwal², Adam L Dorfman ${ }^{1,2}$ \\ From 16th Annual SCMR Scientific Sessions \\ San Francisco, CA, USA. 31 January - 3 February 2013
}

\section{Background}

After repair of tetralogy of Fallot (rTOF), left (LVEF) and right (RVEF) ventricular ejection fraction are important markers of clinical status and outcome, but may not improve after pulmonary valve replacement. Strain is a sensitive marker of ventricular dysfunction, but the potential relation to quality of life in this population has not been evaluated.

\section{Methods}

Fifty-nine patients with rTOF (median age 28 years, range 15-69) underwent cardiovascular magnetic resonance (CMR) from 2008-2009 and completed the Short Form 36 (a validated quality of life assessment). A midventricular short-axis slice was analyzed for left ventricular global circumferential strain (LVGCS) with feature tracking software (TomTec, Unterschleissheim, Germany). A four-chamber slice was analyzed for left ventricular longitudinal strain (LVGLS), and right ventricular longitudinal strain (RVLS), using the three segments of the right ventricular free wall. A subset of 30 patients was re-analyzed for intraobserver and interobserver variability. The physical component summary (PCS) and subscales of physical functioning $(\mathrm{PF})$, role-physical $(\mathrm{RP})$ and general health $(\mathrm{GH})$ were chosen for analysis, and age-adjusted z-score $\leq-1$ was considered a clinically significant decreased quality of life.

\section{Results}

Strain analysis was feasible in 58/59 patients (98\%). LVGCS correlated with LVGLS $(\mathrm{r}=0.45, \mathrm{p}=0.006)$ and LVEF $(r=-0.63, p<0.0001)$. RVLS correlated with LVEF $(\mathrm{r}=-0.29, \mathrm{p}=0.03)$ but not with RVEF. Patients with RVLS below the median had increased odds of decreased PF and GH subscale scores, with strong trends for PCS and RP (Table). Among patients with normal RVEF ( $\geq 45 \%)$ these associations remained significant (PF: OR 9.5, $\mathrm{p}=0.03$; GH: OR 5.9, $\mathrm{p}=0.04$ ). Intraobserver and interobserver variability was acceptable for LVGCS (coefficients of variation 9.5\%, 10.0\%), but lower for LVGLS $(17.2 \%, 16.8 \%)$, and poor for RVLS (19.9\%, 28.8\%).

\section{Conclusions}

Although RVLS reflects right ventricular sinus function and not necessarily overall RVEF, it appears to have discriminative ability in this population for decreased quality of life, and may yield incremental prognostic value beyond global RVEF assessment. However,

Table 1 Odds ratios of age-adjusted z-score $\leq-1$ with strain value below the median. Data presented as odds ratio (95\% confidence interval).

\begin{tabular}{|c|c|c|c|c|}
\hline & PCS & PF & $\mathrm{RP}$ & $\mathrm{GH}$ \\
\hline LVGCS & $1.7(0.5-6.1) p=0.39$ & $2.8(0.8-12) p=0.13$ & $2.7(0.6-14) p=0.19$ & $1.7(0.5-5.5) p=0.40$ \\
\hline LVGLS & $1.7(0.5-6.1) p=0.39$ & $1.2(0.3-4.5) p=0.76$ & $0.6(0.1-2.6) p=0.51$ & $1.2(0.4-3.8) p=0.78$ \\
\hline RVLS & $2.1(0.6-7.3) p=0.12$ & $5.4(1.4-27) p=0.01$ & $3.4(0.8-18) p=0.10$ & $3.5(1.1-13) p=0.04$ \\
\hline
\end{tabular}

${ }^{1}$ Pediatrics and Communicable Diseases, Divsion of Pediatric Cardiology,

University of Michigan, Ann Arbor, MI, USA

Full list of author information is available at the end of the article

(c) 2013 Lu et al; licensee BioMed Central Ltd. This is an Open Access article distributed under the terms of the Creative Commons 
clinical use may be limited by reproducibility. Further study is needed to evaluate techniques to limit variability, and to evaluate longitudinal changes in this population.

\section{Funding}

The authors have nothing to disclose.

Author details

'Pediatrics and Communicable Diseases, Divsion of Pediatric Cardiology, University of Michigan, Ann Arbor, MI, USA. ${ }^{2}$ Radiology, University of

Michigan, Ann Arbor, MI, USA.

Published: 30 January 2013

doi:10.1186/1532-429X-15-S1-E85

Cite this article as: Lu et al:: Right ventricular free wall strain predicts quality of life in repaired tetralogy of Fallot. Journal of Cardiovascular Magnetic Resonance 2013 15(Suppl 1):E85.

Submit your next manuscript to BioMed Central and take full advantage of:

- Convenient online submission

- Thorough peer review

- No space constraints or color figure charges

- Immediate publication on acceptance

- Inclusion in PubMed, CAS, Scopus and Google Scholar

- Research which is freely available for redistribution

Submit your manuscript at www.biomedcentral.com/submit
C BioMed Central 